\title{
Implementation of postpartum intrauterine device (PPIUD) services across 10 districts in Malawi
}

\section{Jennifer H. Tang ${ }^{1,2 *}$, Nenani Kamtuwanje ${ }^{1}$, Prisca Masepuka ${ }^{1}$, Jane Zgambo $^{3}$, Phillimon Kashanga ${ }^{4}$, Caitlin Goggin ${ }^{4}$, Nicky Matthews ${ }^{4}$, Olive Mtema ${ }^{5}$, Ndidza Chisanu ${ }^{6}$, Mary Phiri', Modesta Kasawala ${ }^{7}$, Fannie Kachale ${ }^{7}$}

1. UNC Project-Malawi, c/o Kamuzu Central Hospital, 100 Mzimba Road, Private Bag A-104, Lilongwe, Malawi

2. University of North Carolina at Chapel Hill, Department of Obstetrics \& Gynecology, 100 Manning Road, Campus Box 7570, Chapel Hill, NC, 27599-7570 USA

3. Support for Service Delivery Integration-Services (JHPIEGO), Lilongwe, Malawi

4. Banja La Mtsogolo (Marie Stopes International), Mphatsa House, Lilongwe, Malawi

5. Health Policy Project, Amina House, Paul Kagame Road, Lilongwe, Malawi

6. Family Planning Association of Malawi

7. Reproductive Health Directorate, Malawi Ministry of Health

\section{Background}

Malawi has a high maternal mortality and unmet need for family planning, which could be reduced by improving access to postpartum intrauterine device (PPIUD) insertion. Our objective is to describe the implementation of PPIUD services by 4 local organizations at 14 government health services across 10 districts in Malawi.

Methods

This program was a collaborative effort between the Malawi Ministry of Health's Reproductive Health Directorate and 4 supporting organizations. Training, educational, and monitoring and evaluation materials for PPIUD insertion were developed between December 2013 and April 2014. Each organization was then responsible for PPIUD community sensitization, provider training, and tracking of PPIUD insertions (via PPIUD register books) at their targeted health facilities. Community sensitization activities included Open Day campaigns, which were organized by local leaders to sensitize their communities, and Population Weekends, which were organized by religious leaders to target their congregations.

Results

Community sensitization activities, provider trainings, and mentoring occurred from January 2014 to June 2015, and monitoring and evaluation continued until December 2016 at some sites. One national Radio Discussion Panel with religious leaders was broadcast, 20 Open Day campaigns and 2 Population Weekends were held, 429 providers were trained during 27 trainings, and 249 PPIUD insertions occurred.

Conclusions

PPIUD can be safely offered in Malawi. However, the biggest challenge with program implementation was with encouraging providers to take the extra time and effort to insert an IUD within 48 hours of delivery. In addition, frequent rotation of trained labour ward staff to other clinical areas hindered the program's sustainability since new trainings had to be held whenever staff members were rotated. Further research should be done to determine the best strategies to motivate busy providers to insert PPIUD, and PPIUD should be integrated into both medical and nursing curriculums to reduce the number of postgraduate trainings required to sustain PPIUD services.

Key words: postpartum, intrauterine device, Malawi, family planning, Africa

\section{Introduction}

Malawi has a high maternal mortality ratio and unmet need for family planning (FP) among married women aged 1549 years. ${ }^{1}$ Both could be reduced by improving access to modern FP methods, such as the intrauterine device (IUD), particularly in the immediate postpartum period ( $<48$ hours after delivery). Immediate postpartum intrauterine device (PPIUD) insertion is safe $\mathrm{s}^{2,3}$ and has been implemented in multiple sub-Saharan African countries. ${ }^{4-7}$

A pilot randomized controlled trial of PPIUD versus interval insertion of the copper IUD was completed in 2010-2011 at Bwaila Hospital in Lilongwe, Malawi. ${ }^{8}$ A total of 12 women received PPIUD, whereas 18 received interval IUD. At 12 weeks post-delivery, 28 (93\%) of 30 women were still using the IUD, with no significant difference between the two groups. All women reported that they liked using the IUD and would recommend it to a friend. The authors concluded that PPIUD was acceptable to women who received it, but that enhanced community education, particularly with men, would be needed for more widespread acceptance, which was confirmed in a follow-up qualitative study. ${ }^{9}$

After the pilot study ended, PPIUD also ended at Bwaila, despite having trained a staff of $60 \mathrm{in}$ its provision. Therefore, the Malawi Ministry of Health's $(\mathrm{MoH})$ Reproductive Health Directorate (RHD) began partnering with local organizations to re-implement PPIUD with the copper IUD at Bwaila and other health facilities. The MoH sent two Master FP Trainers to a PPIUD workshop in Zambia in April 2013 to learn how to implement PPIUD services. ${ }^{10} \mathrm{~A}$ report on the workshop was made to the MoH's FP Sub-Committee in June 2013.

Shortly thereafter, the RHD partnered with 4 local organizations who had received grant funding to implement PPIUD at 14 health facilities around the country: UNC Project-Malawi (UNC), Banja La Mtsogolo (BLM, Malawi's 
Sarie Stopes Affiliate), Support for Service Delivery Integration-Services (SSDI, a collaboration between
HPIEGO and Save the Children), and United Nation Population Fund (UNFPA). Our objective is to describe the implementation of PPIUD services by these 4 local organizations at 14 government health services across 10 districts in Malawi.

Method

UNC implemented PPIUD at two facilities, whereas BLM SSDI, and UNFPA each implemented it at 4 facilities (Figure 1). These 14 facilities were chosen by the RHD because of their high volume of deliveries and interest in expanding their $\mathrm{F}$ Malawi (Figure 1). Each organization was responsible for implementing the PPIUD community sensitization, training, and monitoring and evaluation activities at their targeted facilities as no standardized guidelines for implementation
existed. However, the organizations first worked together to produce the PPIUD training presentation, manual, checklist,
proted counseling cases, provider information sheet, pre/posttest, course evaluation, and register. These materials were presented to the FP Sub-Committee for approval in January finalized in April 2014 (Figure 2).



Figure 1: Map of 10 PPIUD Implementation districts in Malaw

The partners also worked with the Malawi Health Education Unit (HEU) to develop a PPIUD brochure and three poster In Chichewa, the most commonly-spoken language in Malawi These materials were pilot-tested by the HEU in three the HEU the next month.

Community sensitization and demand generation

The remaining activities were left to each partner to implemen in their own manner. Community sensitzation was gencrally done by first sensitizing the targeted communities' traditional chiefs to the importance of postpartum FP and PPIUD since they play an inportant role in infuencing the comr beliefs and practices. The partners then worked with the chiefs to establish FP Community Task Forces, comprised of key members of the targeted communities who could help to organize an Open Day for their community. Open Days were large community gatherings where multiple activities were utillzed to promote $\mathrm{F}$, including songs, dramas, quiz games, and mobile vans that offered FP services on-site. They also included the use of FP Champions (former or current FP users, particularly IUD users), men who were supportive of $\mathrm{FP}$, and local community health workers, to explain the benefits of FP and dispel its myths. To sensitiz men to FP and PFIUD, SSDI organized soccer and bawo (a local board game) tournaments at their Open Days. UNC partnered with Family Planning Association of Malaw (FPAM, Malawis International Planned Parenthood affiliate) to organize its Open Days. Through a grant that only UNC received, it was also able to work with Health Policy Project (HPP, a 5-year USAID-funded project in Malawi) to sensitize religious leaders and their congregations to the benefits of FP. HPP had already been collaborating with the Malaw Ministry of Economic Planning and Development (MEPD) to train and sensitize the religious leaders of the main religious denominations in Malawi about the benefits of FP and the needs to increase its access. Multiple workshop with these religious leaders were held, during which each religious denonination developed strategies and brochure to promote family planning within their religion's teachings. One strategy agreed upon by the various religious leaders was to organize a live radio discussion panel to promote the use of FP. The radio discussion panel was held on January 16, 2014 and was recorde live on Zodiak Radio Station, one of Malawis

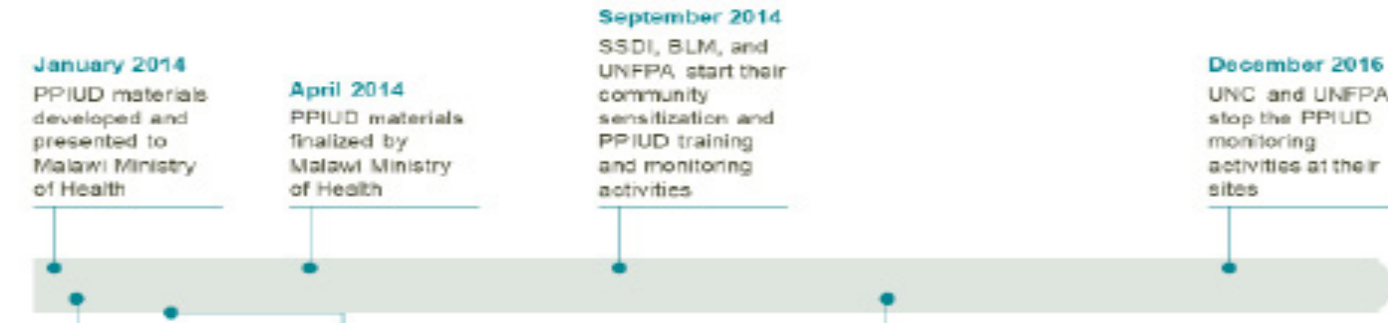
radio stations. The four panelists represente the Malawi Council of Churches and Evangelical Association of Malawi, the Episcopal Conference of Malawi, the Seventh Day Adventist Church in Malawi, and the Quadria Muslim Association of Malawi. This distribution of panelists was chosen
because $69 \%$ of $\begin{array}{cc}\text { because } & 69 \% \text { of } \\ \text { Malawians } & \text { are Christian }\end{array}$

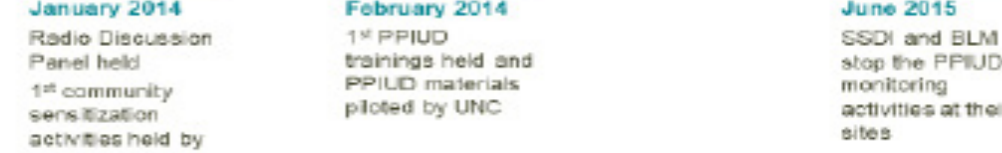
Figure 2: Timeline of PPIUD Implementation activities Figure Abbreviations: PPIUD = postpartumMalawians are Christian
intrauterine device; UNC = University of North Carolina Project-Malawi; SSDI = Support for Serviceand $26 \%$ are Muslim, with
Delivery Integration-Services; BLM = Banja La Mtsogolo; UNFPA = United Nations Population Fund $6 \%$ subscribing to another Delivery Integration-Services; BLM = Banja La Mtsogolo; UNFPA = United Nations Population Fund $6 \%$ subscribing to another of no religion. "The Panelists focused on highlighting the help of the traditional chiefs, 13 FP Task Forces were created, structures each denomination had in support of FP, clearing 5 of which were created by UNC/FPAM (Table 1). Each misconceptions on religion's stance on FP, and focusing on initial UNC/FPAM Task Force Meeting was attended by children and slow down rapid population growth.

The panel also served as an advertisement for Population Weekends, which were held in UNC's two targeted districts. The Population Weekends were held in Kasungu Distric from 17 to 19 January, 2014, and in Area 25 from 31 January to 2 February, 2014. During the Population Weekends, the participating churches and mosques focused their weekend sermons, songs, bible studies, and youth group meetings on FP and gave out FP brochures designed by each of the three major religious denominations in Malawe (Protestant, Catholic, and Muslim). Each brochure focused on the benefits of FP and healthy birth spacing and quoted supporting verses from the Bible or Quran. Brochures were
also produced on adolescent sexuality for use by youth groups. Immediately after the Population Weekends, FPAM held their Open Day campaigns in the same areas targeted by the Population Weekend.

Training, mentoring, monitoring and evaluation

Provider training and mentoring in PPIUD insertion began in February, 2014, and included training in both post-placental IUD insertion (0-10 minutes after placental delivery) and immediate postpartum IUD insertion (10 minutes to 48 hours after placental delivery), as well as IUD removal and management of missing IUD strings. Trained providers included community midwives, husse midwife technicians, registered nurse midwives, medical assistants, and clinical officers. Only clinical officers were trained in intracesarean UD insertion since they were the only trained cadre allowed to perform cesarean sections. They were all trained in the Classroom over two days using the Mama-U Postpartum The the rainer (Lactal Global Health, Stavanger, Norway). The trainers were then placed at the targeted health facility for the remaining three days whenever it was possible


pracice on actual paticnts with supervision. Each facility was given PrIUD instrument kits, including long placental Kely

The initial trainers were 5 American gynecologists and one of the Malawian Master FP Trainers trained in Zambia. These trainers then trained Malawian providers to become trainer. After each training, each trained provider was paired with a Malawian FP mentor. For mentoring, the mentors would meet with their mentees on a monthly basis to monitor any problems or successes they had with PPIUD, for up to 6 months after the training. Monitoring and evaluation was done through monthly visits to the facilities, during which the number of PPIUD insertions was collected through
review of the facility's PPIUD register book, in which all review of the facility's PPIUD register book, in which al
PPIUD insertions were recorded. Due to the end of one of the grant sources for this project, BLM and SSDI only of the grant sources for this project, BLM and SSDI only UNFPA monitored their sites with other grant funding until UNFPA monitored their sites with other grant funding unt

Results

We found that the traditional chiefs for all of our targeted communities accepted our plan to promote postpartum FP and introduce PPIUD among their constituents. With the
60 members of the community, including traditional chiefs, Development and Health Committee members, government employees, and women and youth representatives. The Task Forces helped FPAM to organize participatory action meetings with a multimedia presentation called "Malawi (nvesting in our future now". PSDI created a Task Force in efch of the two districts it was working in. During its Task Fon W. Pres the $\mathrm{MoH}$ BLM officers, and community leaders. We subsequently held 20 Open Day campaigns with the help of 57 trained .

program at 10 health facilities across 6 districts in Malawi (January 2014-June 2015)

\begin{tabular}{|l|l|}
\hline ACTIVITY & OUTPUT \\
\hline $\begin{array}{l}\text { Community } \\
\text { mobilization/demand creation }\end{array}$ & $\begin{array}{l}13 \text { task forces created } \\
\text { among 6 Districts }\end{array}$ \\
\hline $\begin{array}{l}\text { Creation of family } \\
\text { planning task forces }\end{array}$ & $\begin{array}{l}57 \text { family planning champions } \\
\text { established }\end{array}$ \\
\hline $\begin{array}{l}\text { Establishment of family } \\
\text { planning champions }\end{array}$ & $\begin{array}{l}\text { 20 Open Day campaigns } \\
\text { held in } 6 \text { Districts }\end{array}$ \\
\hline Open Day Campaigns & $\begin{array}{l}\text { 1 Panel held with >400 listeners } \\
\text { texting in }\end{array}$ \\
\hline $\begin{array}{l}\text { Radio Discussion Panel } \\
\text { with religious leaders }\end{array}$ & $\begin{array}{l}\text { 2 Population Weekends held in } \\
\text { 2 Districts }\end{array}$ \\
\hline $\begin{array}{l}\text { Population Weekends } \\
\text { with religious leaders }\end{array}$ & 27 trainings held \\
\hline $\begin{array}{l}\text { Provider training, } \\
\text { mentoring, and insertion }\end{array}$ & $\begin{array}{l}429 \text { providers trained } \\
\text { and mentored }\end{array}$ \\
\hline PPIUD training held & 249 PPIUDs inserted \\
\hline $\begin{array}{l}\text { Providers trained and } \\
\text { mentored in PPIUD }\end{array}$ & PPIUD insertions
\end{tabular}

Abbreviations: PPIUD=postpartum intrauterine device

The radio discussion panel was attended by over 100 people, nd over 400 listeners texted in questions and comments. Aproxim tely $78 \%$ of the country's population (10 million) During the Population Weekends, 45,000 brochures were stributed. HPP sampled 10 churches and 2 mosques in Kasungu and 6 churches and 2 mosques in Lilongwe and 列 participated, with an estimated reach of 350,000 Christians nd 5,600 Muslims.

total of 429 government providers were trained and Project held 11 training sessions and trained 101 providers sessions and trained 249 providers between September 2014 and February 2015, whereas BLM held 5 training sessions and rained 67 providers between September and October 2014. Finally, UNFPA held 1 training and trained 16 providers in Pealth workers and other health staff were oriented to

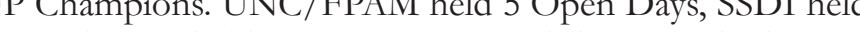
, and mentored in PPIUD during the 27 trainings (Table 2). UNC 
We were unable to monitor individual-level follow-up data implementers, so we do not know how many PPIUDs each of the trained providers inserted. However, given that we trained 429 providers and only 249 PPIUD insertions were
recorded, we know that not all trainees placed a PPIUD on a patient. In addition, during our monitoring visits, we learned that many of the health facilities had only a few interested
providers placing most of the PPIUDs and that the number of PPIUD insertions would decrease when these interested providers were moved to other health facilities or nonand motivated providers affected the sustainability of our program given that providers in Malawi are commonly moved from one ward to another after just a few months.

Table 2: Number of trainings, providers trained, and postpartu
intrauterine devices inserted at each targeted health facility

\begin{tabular}{|l|l|l|}
\hline HEALTH FACILITY & $\begin{array}{l}\text { \# } \\
\text { providers } \\
\text { trained }\end{array}$ & $\begin{array}{l}\text { \# PPIUD } \\
\text { inserted }\end{array}$ \\
\hline A. NORTHERN REGION & & \\
\hline 1. Mzimba District & & \\
\hline Mapale Health Center (BLM) & 18 & 10 \\
\hline Mzuzu Central Hospital (BLM) & 15 & 29 \\
\hline 2. Nkhata Bay District & & \\
\hline $\begin{array}{l}\text { Nkhata Bay District Hospital } \\
\text { (UNFPA) }\end{array}$ & 4 & 3 \\
\hline B. CENTRAL REGION & & \\
\hline Dedza District & & \\
\hline Dedza District Hospital (UNFPA) & 3 & 0 \\
\hline Kasungu District & & \\
\hline Kasungu District Hospital (UNC) & 64 & 32 \\
\hline Lilongwe District & & \\
\hline Area 25 Health Center (UNC) & 37 & 28 \\
\hline Bwaila Hospital (SSDI) & 127 & 12 \\
\hline Mchinji District & & \\
\hline Mchinji District Hospital (BLM) & 13 & 52 \\
\hline C. SOUTHERN REGION & & \\
\hline Blantyre District & & \\
\hline Limbe Health Center (BLM) & 20 & 8 \\
\hline Chiradzulu District & & \\
\hline $\begin{array}{l}\text { Chiradzulu District Hospital } \\
\text { (UNFPA) }\end{array}$ & 3 & 0 \\
\hline Mangochi District & & \\
\hline Mangochi District Hospital (UNFPA) & 3 & 3 \\
\hline Zomba District & & 39 \\
\hline Matawale Health Center (SSDI) & 20 & 29 \\
\hline Domasi Health Center (SSDI) & 18 & 4 \\
\hline Zomba Central Hospital (SSDI) & 84 & 429 \\
\hline TOTAL & & \\
\hline
\end{tabular}
postpartum visit. During our monitoring vists we were only about 24 hours postpartum. The fourth expulsion occurred bout 6 months after delivery, when the IUD strings were found missing on speculum exam. A pelvic x-ray was performed, and no intracorporeal IUD was noted, leading the providers to believe that the IUD had been expelled. tor un

\section{Discussion}

PPIUD is safe and acceptable in Malawi. We had only 4 known expulsions $(1.8 \%)$ out of 249 insertions, which is consistent with other studies performed in Africa, which ranged from $0.8 \%-17 \% \%^{2-8}$. IUD misconceptions, even among providers, have been found in sub-Saharan Africa, including in Malawi ${ }^{4,21418}$. Since many Malawian women seek permission from their husband before accepting an FP method, men must be educated about PPIUD for PPIUD programs to be successful ${ }^{9,1,1,1,1}$. Organizing Open Days and soccer and baws tournaments were successful strategies to reach and sensitize many men at once. We also found that it was important to disseminate information about PPIUD to women during antenatal visits so that they have time to discuss it with their partners. Traditional chiefs and religiou leaders were generally receptive to learning about the benefits of FP and to disseminate this information to their communities and congregations. Our success with religious leaders is likely secondary to the support we received from the Malawi MEPD and the work that HPP had done with sensitizing religious leaders at the highest organizational levels within each of the denominations. The need to involve religious leaders in programs and interventions to increase FP has become increasingly recognized and supported by the literature ${ }^{20,2}$

Many providers trained in PPIUD never placed one on a patient during their trainings due to low numbers of interested patients, despite our efforts to time the community was difficult to time the delivery of interested patients with the trainings, and the low numbers of PPIUD inserted led to less provider confidence in placing them after the trainings. In addition there was often provider rotation out of the lab and postnatal wards every 3-6 months, which led to the nou providers. In Kenya one program t a Provincial Hospital found a PPIUD provider retention rate of only $28 \%$ after $2-3$ years of PPIUD implementation. The issue of high staff turnover and transfer among facilitics made it difficult to ensure that there were always trained providers available for interested patients $4,6-7$. Our biggest challenge with program implementation has been with encouraging providers to take the extra time and effort to insert PPIUD. UNC placed an on-site mentor at Area 25 Health Center after the trainings there but she found the the providers often said that they were too busy to inset PPIUD when the opportunity arose. However Area 25 had the highest number of PPIUDs phaced at, which to the fact that it was monitored for the longest time and


IUD providers at high volume public sector facilities was found to be a successful strategy in a program in Zambia ${ }^{2}$. Further research should be done to determine the best strategies to motivate busy providers to insert PPIUD.

Some of the larger hospitals had fewer PPIUD insertion than the smaller facilities. This finding may have resulte from the fact that the larger hospitals were busier and ha more rotating staff members. In addition, patients were often referred to them from other health centers and already in active labour. In contrast, some of the smaller health facilitie had problems with sterilizing their PPIUD kits because the did not have sterilizers and had to send their kits to the larger hospitals for sterilization, which led to some missed opportunities for PPIUD insertion. Lower PPIUD insertion rates at Kasungu may be due to the implementation of both immediate postpartum implant and PPIUD insertion there as part of another study, which will compare their 2-year continuation rates. During the 7 -month study enrollmen period, 13 PPIUDs and 176 immediate postpartum implant were placed, which suggests a preference for implants ove IUDs when both are avaliable. Now that the World Healt Organization has upgraded implant insertion $<48$ hours after delivery from Category 3 to Category 2 for breastfeeding
women, Malawi has also allowed implants to be placed women, Malawi has also
immediately postpartum

A final challenge that we met was with sustainability. Most FP trainings in Malawi are sponsored by donors. Therefore, once funding for the trainings ended, the trainings also ended. We recommend that this challenge be addressed by integrating PPIUD into existing FP curriculums at the nursing an medical schools, so that these expensive postgraduate trainings become unnecessary. We also recommend that PPIUD training should be integrated into the long-tern P trainings currently held, so that providers do not atten separate trainings for interval and PPIUD insertion. Finally, the labour ward is often the busiest ward; so many provider do not want to work there. Since providers are paid the same wacilities often feel obligated to rotate the providers out of the labour ward after 3-6 months, which affects program sustainability. One possible solution is to compensate labou ward providers at higher levels. Challenges with sustainability of PPIUD has been noted in other countries ${ }^{4,5}$. Strength of our project included collaboration between multiple partners with the RHD and other ministries to implemen PPIUD services across the country. Weaknesses included our limited ability to monitor PPIUD outcomes individually and longitudinally, as well as challenges in finding interested PPIUD clients during the trainings and motivating the busy providers. We were also unable to track the number of deliveries that occurred at each of the 14 health centers; so we cannot present an overall proportion of postpartum women who opted for PPIUD. A final limitation is ou inability to present the total cost for all of our activities to inform future scalability since funding for these PPIUD activities came from multiple sources, including in-kind administrative and financial support from each partner, and funds for these activities were sometimes mixed with othe programmatic activities. However, we hope that the lessons learned from this project will help to improve future PPIUD

\section{Conclusions}

PPIUD services can be safely offered in Malawi. Further research should be done to determine the best strategie to motivate busy providers to insert PPIUD, and PPIUD training should be integrated into both medical and nursing curriculums to reduce the number of postgraduate trainings required to sustain PPIUD services.

\section{Disclosure}

Dhe authors declare no potential conflicts of interest.

\section{Acknowledgments}

We would like to thank all participating organizations, health facilities, communities, religious bodies, churches, and mosques for their support. In addition, we would like
to thank Drs. Dawn Kopp, Peggy Ye, Leann Griffin, and Luu Ireland and the Fellowship in Family Planning for providing their support in training providers in PPIUD for this program. Finally, we would like to thank the World Bank (DGF File \#304414-78) and the Bill \& Melinda Gates Foundation (OPP\#1090837) for their financial support of this program.

\section{References}

- National Statistical Office (NSO) [Malawi] \& ICF. Malaw USA: NSO and ICF; 2017

. Lopez LM, Bernholc A, Hubacher D, Stuart G, Van Vliet HA. Immediate postpartum insertion of intrauterine device for 10.1002/14651858.CD003036.pub3.

3. Sonalkar S, Kapp N. Intrauterine device insertion the postpartum period: A systematic review. Eur J Contracept Reprod

. Charurat E, Ayuyo CM, Muthoni J, Kamunya R, Archer L, Koske $\mathrm{N}$, et al. An assessment of postpartum intrauterine contraceptive device services in Embu, Kenya. Embu, Kenya: ACCESS, 2011 Feb. Associate Cooperative Agreement \#GHS-A-00-04-00002-00. Sponsored by

5. Eluwa GIE, Atamewalen R, Odogwu K, Ahonsi B. Success providing

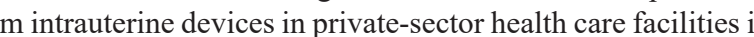
Nigeria: Factors associated with uptake. Glob Health Sci Pract. 2016; (2):276-283. doi: 10.9745/GHSP-D-16-00072.

6. Pfitzer A, Mackenzie D, Blanchard H, Hyjazi Y, Kumar S, Lisanework $\mathrm{N}$, et al. A facility birth can be the time to start family planning: Gynaecol Obstet. 2015;130 (Suppl 2)
SS54-61. doi: 10.1016/j. ijgo.2015.03.008

7. Pleah T, Hyjazi Y, Austin S, Diallo A, Bao B, Waxman R, et al. 7. . 16,4 Suppl 2:S140-152. doi: 10.9745/GHSP-D-16-00039.

8. Bryant AG, Kamanga G, Stuart GS, Haddad LB, Meguid T, Mhango C. Thithere postpartum versus 6-week intrauterine device insertion: a 2013;17(2):72-79.

9. Bryant AG, Hamela G, Gottert A, Stuart GS, Kamanga G. Reason 9or intrauterine device use, discontinuation, and non-use in Malawi: qualitative study of women and their partners. Afr J Reprod Health.
2015;19(4):50-57. 
10. Maternal and Child Health Integrated Program (MCHIP). PPIUCD services: start-up to scale-up regional meeting Zambia (meeting report). Lusaka, Zambia: MCHIP, 2013 Apr 9-12. Associate Cooperative Agreement \#GHS-A-00-08-00002-000. Sponsored by USAID.

11. Kohler HP, Watkins SC, Behrman JR., Anglewicz P, Kohler IV, Thornon RL, et al. Cohort Profile: The Malawi Longitudinal Study of Families and Health (MLSFH). Int J Epidemiol. 2015;44(2):394-404.

12. Population Reference Bureau. Malawi: Investing in our future now. Lilongwe, Malawi: Population Reference Bureau-Malawi;2012 May. Sponsored by USAID.

13. Health Policy Project. Engaging religious leaders in family planning and population issues: report on Population Weekend with religious leaders in Kasungu and Lilongwe Districts. Lilongwe, Malawi: Health Policy Project; 2014 Feb. Contract No.: OPP 1090837. Sponsored by the Bill \& Melinda Gates Foundation.

14. Haddad LB, Feldacker C, Jamieson DJ, Tweya H, Cwiak C, Bryant AG, et al. Medical eligibility, contraceptive choice, and intrauterine device acceptance among HIV-infected women receiving antiretroviral therapy in Lilongwe, Malawi. Int J Gynaecol Obstet. 2014;126(3):213216. doi: 10.1016/j.ijgo.2014.03.026,

15. O'Shea MS, Rosenberg NE, Hosseinipour MC, Stuart GS, Miller WC, Kaliti SM, et al. Effect of HIV status on fertility desire and knowledge of long-acting reversible contraception of postpartum Malawian women. AIDS Care. 2015;27(4):489-498. doi: 10.1080/09540121.2014.972323.

16. Mwafulirwa T, O’Shea M, Hamela G, Samuel E, Chingondole C, Chipangula V, et al. Family planning providers' experiences and perceptions of long-acting reversible contraception in Lilongwe, Malawi. Afr J Reprod Health. 2016;20(2):62-71.

17. Gutin SA, Mlobeli R, Moss M, Buga G, Morroni C. Survey of knowledge, attitudes and practices surrounding the intrauterine device in South Africa. Contraception. 2011;83(2):145-150. doi: 10.1016/j. contraception.2010.07.009.

18. Tilahun Y, Mehta S, Zerihun H, Lew C., Brooks MI, Nigatu T, et al. Expanding access to the intrauterine device in public health facilities in Ethiopia: A mixed-methods study. Glob Health Sci Pract. 2016;4(1):1628. doi: 10.9745/GHSP-D-15-00365.

19. Hartmann M, Giles K, Shattuck D, Kerner B, Guest G. Changes in couples' communication as a result of male-involvement family planning intervention. J Health Commun. 2012;17(7):802-819. doi: 10.1080/10810730.2011.650825.

20. Faith to Action Network. Faith Pre-Conference: the role of faith communities in FP advocacy \& services towards achieving the sustainable development goals (SDGs). Proceedings of the $4^{\text {th }}$ International Conference on Family Planning; 2016 Jan 23-25; Nusa Dua, Indonesia.

21. World Vision. Faith leaders and family planning: a review of the literature plus resources. Federal Way (WA): World Vision, 2016. Sponsored by World Vision.

22. Neukom J, Chilambwe J, Mkandawire J, Mbewe RK, Hubacher D. Dedicated providers of long-acting reversible contraception: New approach in Zambia. Contraception. 2011;83(5):447-452. doi: 10.1016/j.contraception.2010.08.021.

23. World Health Organization. Medical eligibility criteria for contraceptive use, $5^{\text {th }}$ Edition, 2015. Sponsored by the World Health Organization. 